\title{
Comparison of the performance of different mixing ventilation configurations in particle removal from indoor spaces
}

\author{
C. Habchi ${ }^{1}$, K. Ghali ${ }^{2}$ and N. Ghaddar ${ }^{2}$ \\ ${ }^{1}$ Mechanical Engineering Department, Faculty of Engineering, \\ Lebanese University, Branch II, Roumieh, Lebanon \\ ${ }^{2}$ Department of Mechanical Engineering \\ American University of Beirut \\ P.O. Box 11-0236, Beirut 1107-2020, Lebanon \\ Phone/Fax number: +961 1 340460, Ext.3438, e-mail: ka04@aub.edu.lb
}

\section{Key words}

Mixing ventilation, removal efficiency, suction velocity, air quality, outlet location

\begin{abstract}
Re-suspended particles from indoor sufaces present a real threat to occupants. The ventilation system plays a primordial role in enhancing the indoor air quality. A CFD model was developed to compare particle removal effectiveness of variable mixed air distribution configurations. A parametric study was performed to assess the effect of two main factors affecting the airflow pattern: the relative inlet/outlet location and suction velocity.

It was found that the mixing ventilation configuration with floor outlets located at middle of the walls presented the best performance due to the creation of a suction effect covering the majority of the floor area leading to high removal effectiveness. Furthermore, increasing the suction velocity strengthened the suction effect resulting in better particle removal by the escape of a larger number of particles generated at floor level.
\end{abstract}

\section{Introduction}

Indoor aerosol particles constitute high risks to the human health $[1,2,3]$. These particles originate from variable indoor and outdoor sources covering a wide range of sizes [4] and are present on the different indoor surfaces as floors, carpets, mattresses [5]. Cleaning and vacuuming constitute common techniques of dust removal from indoor environments but are not capable of removing all particles accumulated on surfaces [5] presenting reservoir for the contaminated particles.

Particles stored on indoor surfaces and floors might be reintroduced to air by re-suspension. Re-deposited particles present a serious threat to humans breathing close to surfaces seeded with particles and dust [6-7]. Particle re-suspension can take place under the influence of variable flow mechanisms [8-9]. Deposited particles disturbed by variable mechanical activities can resuspend increasing the possibility of occupant contamination [10]. People activities (e.g. dusting, walking, crawling, and vacuuming) were shown to contribute significantly to indoor re-suspension [11-16].

Heating ventilation and air conditioning (HVAC) systems should decrease the indoor contaminants' concentration and ensure minimal deposition and redeposition on surfaces and floors. The aim of this work is to compare the effectiveness of different mixed air distribution configurations in the removal of resuspended particles from indoor occupied space for particle generation at floor level.

For this purpose, the ANSYS Fluent software was used to develop a CFD model. Taking into consideration the contribution of re-suspension to people infection by the inhalation process $[17,18]$, it is necessary to come up with engineering design strategies for removal of indoor pollutants. Therefore micro particles transport physics should be well understood and modeled. HVAC systems should not only ensure thermal comfort of occupants but also reduce the level of pollutants concentration and ensure minimal deposition and re-deposition fractions over surfaces and floors [19, 20].

One of the conventional HVAC methods are the mixed ventilation (MV) system characterized by the ceiling location of supply and return vents [21] and displacement ventilation (DV). These common configurations might not be efficient in removing floor generated particles due to the opposing gravitational settling hindering particle upward motion to reach the exhaust level [23, 24]. Therefore, it is important to control the particle transport in enclosed environments and particularly in case of particle generation from floor level (as in the case of a vacuuming session for example). Hence, there is a need for the design of ventilation 
system with appropriate locations of the supply/return air vents for optimal removal of pollutants.

\section{Problem description}

Figure 1 illustrates the conditioned space and the variable configurations of $\mathrm{MV}$ systems investigated. All MV configurations investigated shared the inlet vent location at top north wall but differed by the placement level of the outlet. Exhaust location is expected to largely affect particle behavior since it modifies the airflow circulation pattern. The location of an exhaust (LE) can be defined as the distance of its center to the supply jet wall (D) normalized by width of the wall (L) on which is located the exhaust as described below:

$$
\mathrm{LE}=\mathrm{D} / \mathrm{L}
$$

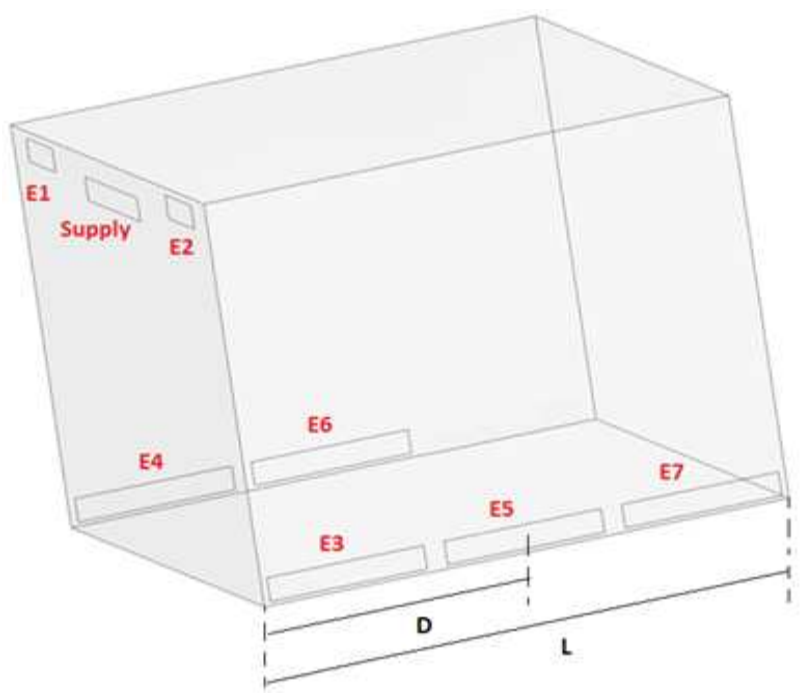

Fig. 1. : Different layouts of MV systems considered through varying the exhausts' location

The variable MV configurations represented in Fig. 1 are described below:

a) Top supply and top return vents (TT configuration) where the supply vent (S) and return vents (E1 and E2) are located at top $(\mathrm{T})$ north wall

b) Top supply and floor return vents $\left(\mathrm{TF}_{\mathrm{oc}}\right.$ configuration) where two exhausts (E4 and E7) are placed at the floor level $(\mathrm{F})$ at the northeast and southwest opposite corners (oc) $\left(\mathrm{LE}_{4}=1 / 6\right.$; $\left.\mathrm{LE}_{7}=5 / 6\right)$

c) Top supply and floor return vents $\left(\mathrm{TF}_{\mathrm{sc}}\right.$ configuration) where two exhausts (E3 and E4) are located at the corners of the air supply wall (sc) $\left(\mathrm{LE}_{3}=1 / 6 ; \mathrm{LE}_{4}=1 / 6\right)$

d) Top supply and floor return vents $\left(\mathrm{TF}_{\mathrm{m}}\right.$ configuration) where two exhausts (E5 and E6 ) are placed at the middle $(\mathrm{m})$ of the east and west walls $\left(\mathrm{LE}_{5}=1 / 2 ; \mathrm{LE}_{6}=1 / 2\right)$ e) Top supply and floor return vents (TFm1 configuration) where one exhaust (E5) is located at the middle $(\mathrm{m})$ of the east wall $(\mathrm{LE} 5=1 / 2)$

f) Floor supply and top return vents (DV configuration) where the supply vent (E5) is placed at floor level while return vents (E1 and E2) are located at top north wall.

\section{Methodology}

\subsection{CFD Model}

To CFD modeling constitute a viable tool in assessing the performance of indoor ventilation systems. CFD has shown high efficiency in literature in terms of computing airflow velocity and temperature profiles and distribution of particles of variable diameters and densities in indoor spaces [25-26]. For this reason, CFD modeling was used in this work to investigate the performance of different mixing configurations in particle removal.

A detailed CFD model was developed to predict the airflow and concentration fields using the commercial software ANSYS FLUENT. Modeling of the different flow physics insures robust CFD results. The Eulerian approach was selected to simulate the indoor room air since it can be assumed as a continuous fluid [27]. Furthermore, the interaction between air and particles was modeled as one way coupling since the discrete phase volume is negligible compared to the indoor space volume [28]. For turbulence modeling, the realizable $k-\varepsilon$ model was adopted since it presents a high accuracy in the prediction of flow behavior involving recirculation in indoor spaces [29]. The energy, momentum $k$ and $\varepsilon$ equations were solved by a second-order upwind discretization scheme. The "PRESTO!" staggered scheme was used to compute the pressure field [30] while the SIMPLE algorithm was adopted for the coupling between pressure and velocity fields [30].

\subsection{Boundary Conditions}

For accurate CFD predictions appropriate boundary conditions should be provided. The space thermal load is resulting from conventional lighting load of $10 \mathrm{~W} / \mathrm{m}^{2}$ [31] $11 \mathrm{~W} / \mathrm{m}^{2}$ from walls. The supply air is characterized by a flow rate of $100 \mathrm{~L} / \mathrm{s}$ at a temperature of $18{ }^{\circ} \mathrm{C}$.

\subsection{Particle Tracking}

To study particles' behavior, the Lagrangian tracking technique which is a discrete trajectory method was used in the CFD model. The Lagrangian method is based on the second law of Newton involving variable forces affecting particle behavior as gravitational, lift and drag forces. 
The effect of local turbulence intensities on particles' trajectories was considered using the discrete random walk model (DRW) which adopts a stochastic approach to compute particles' paths [32]. The particle source in-cell (PSI-C) scheme was adopted for computing the resulting concentrations within the indoor space [29].

In the viscous sub layer, particles can be exposed to very high fluctuating velocities in the normal direction to the wall. This might lead to over-estimation of the frequency of collisions between particles and walls resulting in over-prediction of surface particle deposition which requires appropriate mesh treatment. Thus, in addition to the use of enhanced wall functions near surfaces, surface inflation and face sizing are used for mesh. Figure 2 shows the generated mesh for the computational domain with the corresponding treatment.

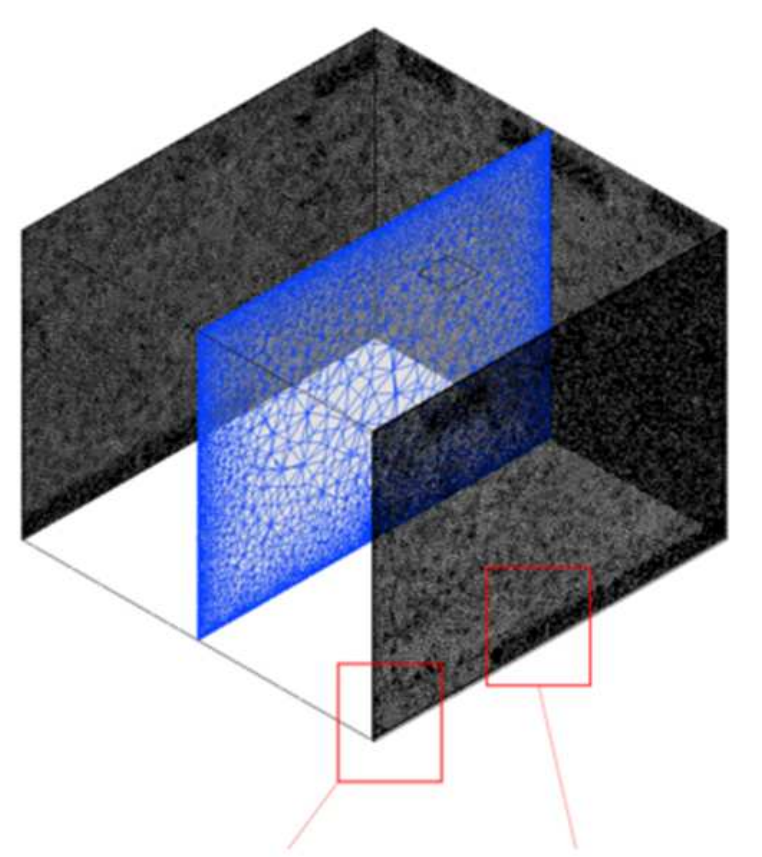

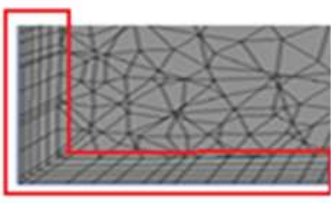

Surface Inflation

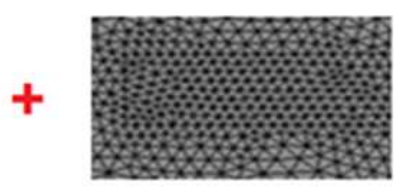

Face Sizing
Fig. 2. : Generated mesh for the computational domain with appropriate treatment

Particle concentration field was predicted by tracking a high number of particles trajectories within the space [33-34]. The implementation of appropriate boundary conditions when particle trajectories reach a surface is primordial for accurate prediction of distribution of particles within the domain of the indoor space. The "escape" boundary condition was adopted at outlets, while to account for particle deposition the "trap" condition was selected when a particle trajectory reached a wall. The escaped and trapped trajectories terminate while the remaining trajectories are tracked within the domain. Particles were generated at floor level from variable positions distributed over the flooring area. The emission locations are presented in Fig. 3.

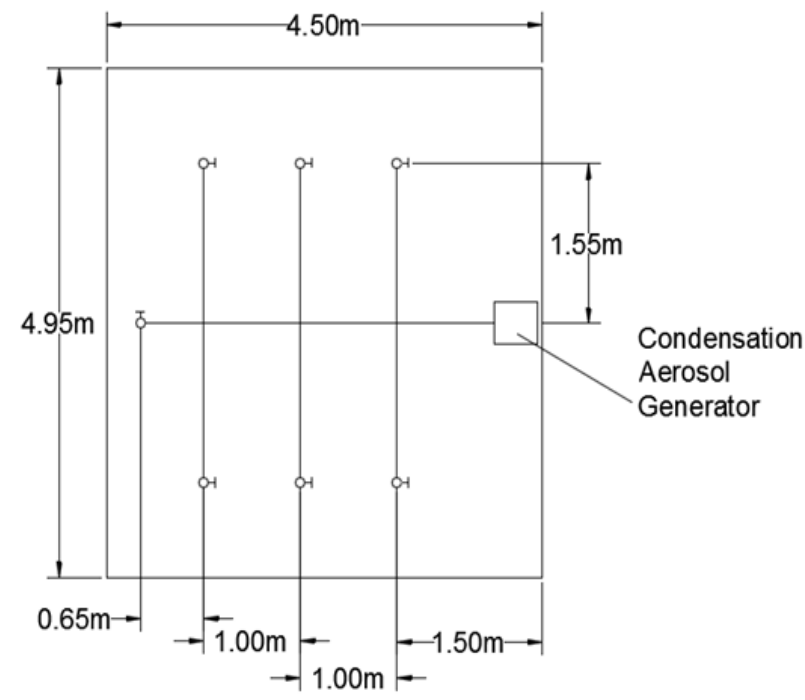

Fig. 3. : Layout of particle generation

Numerical convergence was reached when the following three conditions were satisfied: scaled residuals became lower than $10^{-5}$, domain net heat flux dropped below $1 \%$ of the total heat gain, and particle concentrations within the space were stabilized. A grid independence test was performed to decide on the number of elements required. Temperature and velocity values at 10 randomly selected locations within the domain were compared between meshes to insure statistically reliable results. The number of elements was increased until the maximum relative difference in the predicted values of temperature and velocity between two consecutive meshes became lower than $5 \%$.

For comparison of the removal effectiveness of particles among the different configurations studied an air quality index was introduced. The index represents the percentage of particles removed (PR) calculated as shown by the following equation:

$$
P R=\frac{\text { Number of escaped trajectories tracked }}{\text { Total number of tracked trajectories }} \times 100
$$

\section{Results and discussion}

Numerical CFD simulations of a typical room of dimensions $(3.4 \mathrm{~m} \times 3.4 \mathrm{~m} \times 2.6 \mathrm{~m})$ were conducted. Particles of $1 \mu \mathrm{m}$ in diameter were generated at floor level for the variable layouts considered. The supply air flow rate was fixed to $100 \mathrm{~L} / \mathrm{s}$ for the different MV configurations. A parametric study was performed to assess the effect of two important factors affecting the 
airflow distribution: the relative inlet/outlet location and suction velocity. Table 1 shows the PR for the different configurations studied.

Table 1. : PR for the different configurations studied

\begin{tabular}{|l|l|l|}
\hline $\begin{array}{l}\mathrm{MV} \\
\text { configuration }\end{array}$ & $\begin{array}{l}\text { Suction } \\
\text { velocity } \\
(\mathrm{m} / \mathrm{s})\end{array}$ & PR (\%) \\
\hline $\mathrm{TT}$ & 0.4 & 50.87 \\
\hline $\mathrm{TF}_{\mathrm{oc}}$ & 0.4 & 54.28 \\
\hline $\mathrm{TF}_{\mathrm{sc}}$ & 0.4 & 65.37 \\
\hline $\mathrm{TF}_{\mathrm{m}}$ & 0.4 & 72.16 \\
\hline $\mathrm{TF}_{\mathrm{oc}}$ & 0.8 & 63.94 \\
\hline $\mathrm{TF}_{\mathrm{m}}$ & 0.8 & 75.23 \\
\hline $\mathrm{TF}_{\mathrm{m} 1}$ & 0.8 & 66.23 \\
\hline $\mathrm{DV}$ & - & 35.12 \\
\hline
\end{tabular}

Figure 4 represents the effect of exhaust location on the variation of normalized concentration (ratio of particle concentration to generation concentration) with height. For the typical office space considered, the $\mathrm{TF}_{\mathrm{sc}}$ and $\mathrm{TF}_{\mathrm{m}}$ configurations significantly enhanced the effectiveness of the MV system in particle removal compared to TT configuration. For instance the PR was increased from $50.87 \%$ in case of TT configuration to $65.37 \%$ and $72.16 \%$ in case of $\mathrm{TF}_{\mathrm{sc}}$ and $\mathrm{TF}_{\mathrm{m}}$ respectively (Table 1 and Fig. 4).

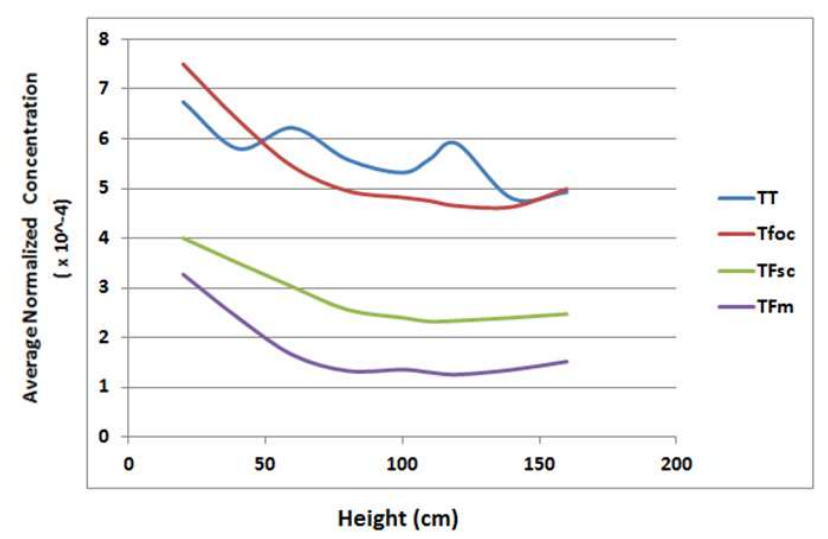

Fig. 4. Comparison of the normalized concentration (ratio of particle concentration to generation concentration) variation with height for different exhaust locations

Figure 5 illustrates the velocity contours at at a plane close to the floor level for the $\mathrm{TF}_{\mathrm{m}}$ configuration. The positive performance of the $\mathrm{TF}_{\mathrm{m}}$ configuration is due to the effective suction resulting in a uniform airflow distribution over the floor area as shown in Fig. 5.

Figure 6 illustrates the normalized concentration contours at a plane close to the floor level for the $T F_{m}$ configuration. Figure 6 shows the cleaning effect created by suction from exhausts conveniently placed. For instance for the $\mathrm{TF}_{\mathrm{m}}$ layout, the outlets located at middle of the walls $(E L=0.5)$ provide a suction effect covering the majority of the floor area leading to high removal effectiveness.

Velocity $(\mathrm{m} / \mathrm{s})$
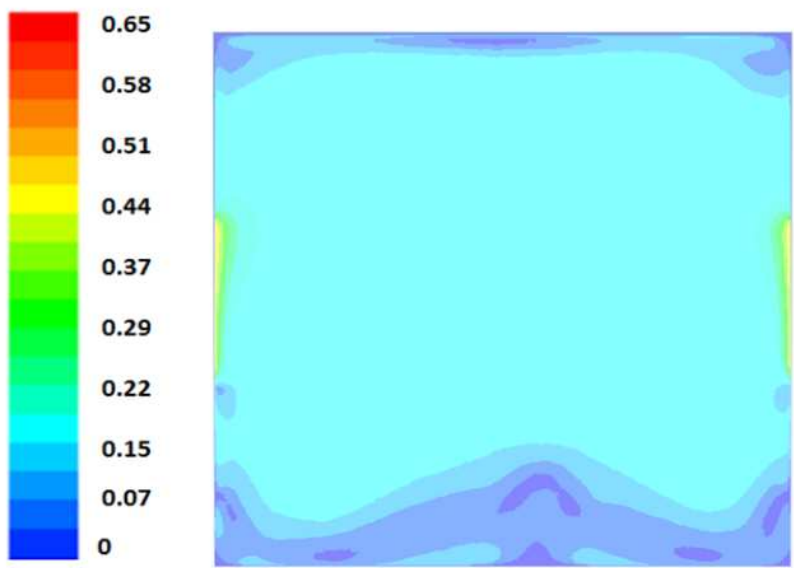

Fig. 5. Velocity contours at a plane close to the floor level for the $\mathrm{TF}_{\mathrm{m}}$ configuration

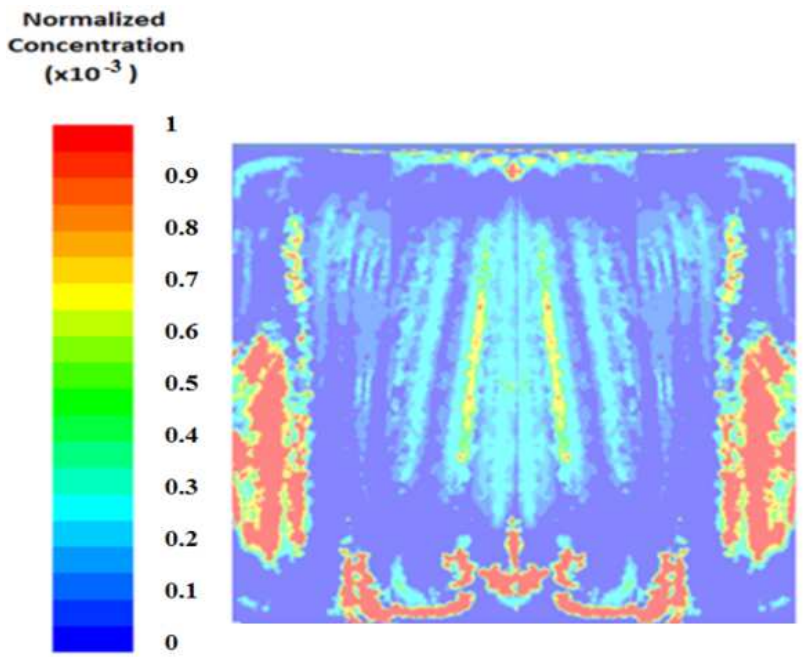

Fig. 6. Normalized concentration contours at a plane close to the floor level for the $\mathrm{TF}_{\mathrm{m}}$ configuration

To assess the effect of suction velocity, two velocities of 0.4 and $0.8 \mathrm{~m} / \mathrm{s}$ were compared for the worst $\left(\mathrm{TF}_{\mathrm{oc}}\right)$ and best layouts $\left(\mathrm{TF}_{\mathrm{m}}\right)$ as presented in Table 1 and Fig. 7. Figure 7 represents a comparison of the normalized concentration variation with height for different suction velocities.

The increase in suction velocity enhanced the performance of the layouts studied especially for the $\mathrm{TF}_{\mathrm{oc}}$ configuration (Fig. 7). For instance, in the $\mathrm{TF}_{\mathrm{oc}}$ case, the PR increased from $54.28 \%$ for a suction velocity of $0.4 \mathrm{~m} / \mathrm{s}$ to $63.94 \%$ for a suction velocity of $0.8 \mathrm{~m} / \mathrm{s}$.

Larger the suction velocity, lower is the normalized concentration within the space for the same configuration. This is explained by the fact that 
increased velocity strengthened the suction effect resulting in better particle removal through the escape of larger number of generated particles at floor level.

Nevertheless, to avoid thermal discomfort of occupants, the possibility of suction velocity increase is limited. The $\mathrm{TF}_{\mathrm{m}}$ configuration presented good performance for acceptable suction velocity and is recommended to be used in mixing ventilated indoor spaces.

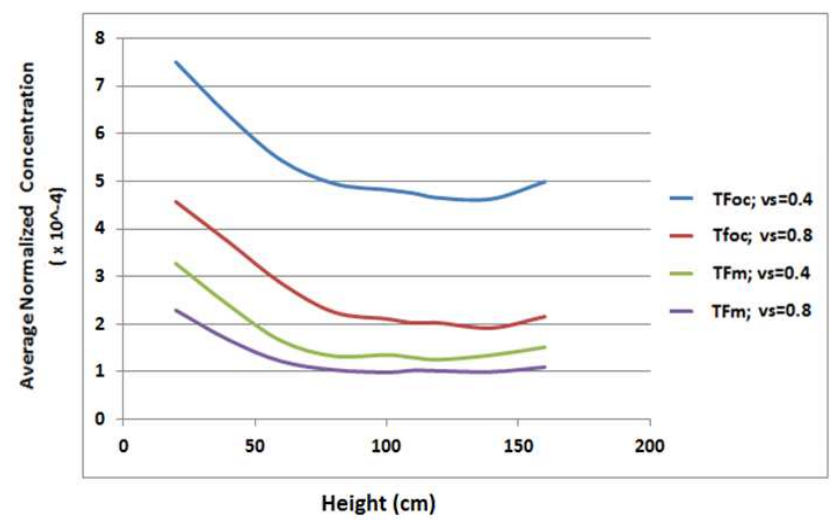

Fig. 7. Comparison of the normalized concentration variation with height for different suction velocities

For the same configuration the number of exhausts largely affected the performance. For instance, $\mathrm{TF}_{\mathrm{m} 1}$ $\left(\mathrm{v}_{\mathrm{s}}=0.8 \mathrm{~m} / \mathrm{s}\right)$ decreased the performance in terms of particle removal compared to $\mathrm{TF}_{\mathrm{m}}\left(\mathrm{v}_{\mathrm{s}}=0.4 \mathrm{~m} / \mathrm{s}\right)$ despite the higher suction velocity used (Table 1). This is explained by the symmetrical suction effect created by the $\mathrm{TF}_{\mathrm{m}}$ configuration where two exhausts were placed opposing each other resulting in a suction effect covering the majority of the floor area avoiding the formation of zones with high particle concentrations (Figs. 5 and 6).

Selecting the appropriate exhausts' location and number, $\mathrm{TF}_{\mathrm{m}}$ configuration allows reaching good performance in terms of IAQ while maintaining thermal comfort since it presents high removal effectiveness with acceptable suction velocity. On the other hand, for the vacuuming application where no occupants are present, increasing the suction velocity can be of great help in increasing particle removal.

The performance of DV in particle removal is largely dependent on particle generation location. In case of generation at floor level bad performance is provided by DV with the lowest PR compared to the different MV configurations studied (Table 1). This can be explained by the upward transport of particles generated at floor level by the supply DV jet and distribution within the indoor space without effective removal from exhaust at ceiling level due to the large distance separating floor generation from ceiling exhaust location.

Therefore, during a vacuuming session the DV system should be turned off to avoid spreading particles resuspended within the space and if possible the air flow should be reversed to act as an MV configuration helping in particle removal from indoors reducing health risks.

\section{Conclusion}

A CFD model was developed to compare the effectiveness of different mixed air distribution configurations in the removal of re-suspended particles from indoor occupied space. The CFD model was used to perform a parametric study to investigate the effect of two factors affecting the airflow pattern: the relative inlet/outlet location and suction velocity.

The $\mathrm{TF}_{\mathrm{m}}$ layout, where two outlets are located at middle of the walls $(E L=0.5)$, presented the best performance due to the creation of a suction effect covering the majority of the floor area leading to high removal effectiveness. For instance the percentage of removed particles was increased from $50.87 \%$ in case of TT configuration to $65.37 \%$ and $72.16 \%$ in case of $\mathrm{TF}_{\mathrm{sc}}$ and $\mathrm{TF}_{\mathrm{m}}$ respectively for a suction velocity of 0.4 $\mathrm{m} / \mathrm{s}$.

Increased suction velocity strengthened the suction effect resulting in better particle removal through the escape of larger number of generated particles at floor level. For example, in the $\mathrm{TF}_{\mathrm{oc}}$ case, the percentage of removed particles increased from $54.28 \%$ for a suction velocity of $0.4 \mathrm{~m} / \mathrm{s}$ to $63.94 \%$ for a suction velocity of $0.8 \mathrm{~m} / \mathrm{s}$.

However, to avoid thermal discomfort of occupants, the increase of suction velocity should be limited. As a conclusion, the $\mathrm{TF}_{\mathrm{m}}$ configuration presented good performance for acceptable suction velocity and is recommended to be used in mixing ventilated indoor spaces.

The performance of DV in particle removal for generation at floor level was the worst compared to the different MV configurations studied. From here, it is recommended during a vacuuming session to turn off the DV system to avoid spreading particles re-suspended within the space or to reverse the air flow pattern from DV to MV mode.

\section{References}

[1] Molhave, L., Kjaergaard, S.K., Attermann, J. Sensory and other neurogenic effects of exposures to airborne office dust, Atmospheric Environment 2000, (34), 4755-4766.

[2] Mendell, M.J., Fisk, W.J., Petersen, M.R., Hines, C.J., Dong, M., Faulkner, D., Deddens, J.A., Ruder, A.M., Sullivan, D., Boeniger, M.F. Indoor particles and symptoms among office workers: results from a double-blind cross-over study, Epidemiology 2002, (13), 296-304.

[3] Schneider, T., Sundell, J., Bischof, W., Bohgard, M., Cherrie, J.W., Clausen, P.A., Dreborg, S., Kildeso, J., Kjaergaard, S.K., Lovik, M., Pasanen, P., Skyberg, K., 'EUROPART' Airborne particles in the indoor environment, A European interdisciplinary review of scientific evidence on associations between exposure to particles in 
buildings and health effects. Indoor Air 2003, (13), $38-48$.

[4] Long, C.M., Helen H. Suh, and Petros K. "Characterization of indoor particle sources using continuous mass and size monitors." Journal of the Air \& Waste Management Association 50.7 (2000): 1236-1250.

[5] Cao, Zhi-Guo, et al. "Particle size: A missing factor in risk assessment of human exposure to toxic chemicals in settled indoor dust." Environment international 49 (2012): 24-30.

[6] Sehmel, G. A. "Particle resuspension: a review." Environment International 4.2 (1980): 107-127.

[7] Ormstad, H., B. V. Johansen, and P. I. Gaarder. "Airborne house dust particles and diesel exhaust particles as allergen carriers." Clinical and experimental allergy 28.6 (1998): 702-708.

[8] Ibrahim, A. H., Dunn, P. F., \& Brach, R. M. (2004). Microparticle detachment from surfaces exposed to turbulent air flow: Effects of flow and particle deposition characteristics. Journal of Aerosol Science, 35(7), 805-821.

[9] Habchi, C., Ghali, K., \& Ghaddar, N. (2016). Coupling CFD and analytical modeling for investigation of monolayer particle resuspension by transient flows. Building and Environment, 105, 1-12. [10] Wallace, L. (2006). Indoor sources of ultrafine and accumulation mode particles: size distributions, size-resolved concentrations, and source strengths. Aerosol science and technology, 40(5), 348-360.

[11] Roberts, J. W., D. E. Camann, and T. M. Spittler. "Reducing lead exposure from remodeling and soil track-in in older homes." A AND WMA ANNUAL MEETING. Vol. 15. AIR \& WASTE MANAGEMENT ASSOCIATION, 1993.

[12] Corsi, Richard L., Jeffrey A. Siegel, and Chunyi Chiang. "Particle resuspension during the use of vacuum cleaners on residential carpet." Journal of occupational and environmental hygiene 5.4 (2008): 232-238.

[13] A.R. Ferro, R.J. Kopperud, L.M. Hildemann. Source strengths for indoor human activities that resuspend particulate matter. Environmental Science \& Technology, 38 (2004), pp. 1759-1764.

[14] Abt E., H.H. Suh, P. Catalano, P. Koutrakis: Relative contribution of outdoor and indoor particle sources to indoor concentrations, Environmental Science and Technology, 34, 3579-3587 (2000).
[15] Gomes C, Freihaut J, Bahnfleth W. Resuspension of allergen-containing particles under mechanical and aerodynamic disturbances from human walking. Atmospheric Environment 2007;41:5257e70.

[16] Kazzaz M, Habchi C, Ghali K, Ghaddar, N, Alotaibi S, Chakroun W (2017). Micro-particle indoor resuspension under periodic airflows: A numerical-analytical study and experimentations. Building and Environment, 123, 299-314.

[17] Bruce N, Perez-Padilla, R, Albalak R. Indoor air pollution in developing countries: a major environmental and public health challenge. Bulletin of the World Health Organization 2000; 78(9): 1078-1092.

[18] Spengler, J D, Sexton K. Indoor air pollution: a public health perspective. Science 1983; 221(4605): 9-17.

[19] Gradoń, Leon. "Resuspension of particles from surfaces: technological, environmental and pharmaceutical aspects." Advanced Powder Technology 20.1 (2009): 17-28.

[20] Makhoul, A., K. Ghali, and N. Ghaddar. Lowmixing coaxial nozzle for effective personalized ventilation, Indoor and Built Environment. 24 (2), pp. 225-243 2015.

[21] Todorovic, M., et al. Natural and mixed ventilation design via CFD and architectural modelling. International Journal of Ventilation 5.4 (2007): 447-458.

[22] Brohus H, Knudsen HN, Nielsen PV, Clausen G, Fanger PO. Perceived air quality in a displacement ventilated room. Indoor Air. Proceedings of the 7th Int. Conf. on Indoor Air Quality and Climate, Nagoya, Japan 1996; 1: 811816.

[23] Zhang, Z., and Q. Chen. "Experimental measurements and numerical simulations of particle transport and distribution in ventilated rooms." Atmospheric environment 40.18 (2006): 3396-3408.

[24] Brohus H, Nielsen PV. Personal exposure in displacement ventilated rooms. Indoor Air. 1996 Sep;6(3):157-67.

[25] Makhoul A, Ghali K, Ghaddar N. The energy saving potential and the associated thermal comfort of displacement ventilation systems assisted by personalized ventilation. Indoor Built Environment 2013; 22: 508-519. 
[26] Zhang, Q. Chen, Comparison of the Eulerian and Lagrangian methods for predicting particle transport in enclosed spaces. Atmospheric Environment 41 (2007) 5236-5248.

[27] F.Z. Chen, S. Yu, A. Lai, Modeling particle distribution and deposition in indoor environments with a new drift-flux model. Atmospheric Environment 40 (2006) 357-367.

[28] ANSYS Software: ANSYS Inc. http://www.ansys.com/

[29] Z. Zhang, Q. Chen, Experimental measurements and numerical simulations of particle transport and distribution in ventilated rooms. Atmospheric Environment 40(18) (2006) 3396-3408.

[30] C. Habchi, K. Ghali, N. Ghaddar, W. Chakroun, S. Alotaibi, Ceiling Personalized Ventilation Combined with Desk Fans for Reduced Direct and Indirect Cross-Contamination and Efficient use of an Office Space. Energy Conversion and Management 111 (2016) 158-73.

[31] C. Habchi, W. Chakroun, S. Alotaibi, K. Ghali, N. Ghaddar, Effect of shifts from occupant design position on performance of ceiling personalized ventilation assisted with desk fan or chair fans. Energy and Buildings 117 (2016) 20-32.

[32] ANSI/ASHRAE Standard 90.1: Energy Standard for Buildings Except Low-Rise Residential Buildings. Atlanta, American Society of Heating, AirConditioning and Refrigeration Engineers, Inc.; 2013.

[33] M. Wang, C.H. Lin, Q. Chen, Advanced turbulence models for predicting particle transport in enclosed environments. Building and Environment 47 (2012) 40-49.

[34] Makhoul A, Ghali K, Ghaddar N. Investigation of Particle Transport in Offices Equipped with Ceiling-Mounted Personalized Ventilators. Building and Environment 2013; 63: 97-107. 